\title{
That Joke Isn't Funny Anymore: Racial Microaggressions, Color-Blind Ideology and the Mitigation of Racism in English Men's First-Class Cricket
}

\author{
Daniel Burdsey \\ University of Brighton
}

This article investigates the presence and effects of racial microaggressions in English first-class cricket. Drawing on interview data with British Asian players, it not only highlights players' experiences of racism, but also identifies their tendency to downplay the repercussions of some of the forms that this prejudice takes. The analysis demonstrates that color-blind ideology is so entrenched in contemporary Western sport that its reproduction is not exclusively the preserve of white groups; it can also at times compel minority ethnic participants to endorse dominant claims that the effects of racism are overstated as well. As a consequence they are often pressured into denying or downplaying those forms of verbal discrimination which are articulated between team-mates and in a seemingly playful manner, dismissing incidents as merely "banter" or "jokes".

Cet article porte sur la présence et les effets des micro-agressions raciales au cricket anglais. À partir des données d'entrevues réalisées auprès de joueurs anglo-asiatiques, il met en lumière leurs expériences de racisme et identifie leur tendance à amenuiser les répercussions de certaines des formes d'un tel préjudice. L'analyse suggère que l'idéologie de l'absence de différence raciale est tellement enracinée dans le sport contemporain occidental que sa reproduction n'est pas exclusivement l'apanage des groupes blancs, elle peut aussi parfois contraindre les participants issus de minorités ethniques à entériner un discours dominant selon lequel les effets du racisme sont surévalués. En conséquence, ils sont souvent poussés à nier ou à minimiser ces formes de discrimination verbale qui sont articulées entre coéquipiers d'une façon apparemment ludique, rejetant les incidents comme étant de simples blagues.

For many (although certainly not all) participants, fans, and media commentators, racism in professional sport in the UK is now perceived as largely a thing of the past. Any remnants are seen to be perpetrated by a decreasing number of residual bigots, who reside on the terraces rather than in the locker-rooms, management offices, and boardrooms. Indeed, it is frequently argued that racism at elite club and 
organizational levels must have been eradicated, for any ideology or practice that limits the available pool of talent for selection fundamentally cannot coexist with the overarching desire for sporting success. As Long and McNamee (2004, p. 415) argued, "There seems to be a presumption that self-interest (the success of the team) will override any racism and ensure that players from minority ethnic groups gain the opportunities they deserve." Although few individuals would completely deny that racist incidents still occur on the playing field and in the stands, these are seen as sporadic, spontaneous occurrences caused by the highly-charged, competitive nature of professional sport and/or emanating from individual prejudices (Müller, van Zoonen \& de Roode, 2007). In short, the idea that racial inequality in elite sport is ingrained and permeates many of its structures and institutions is widely shunned.

Through the illustration of a sporting case study, this article provides an empirical insight into the manifestations and implications of this view. It endorses Goldberg's $(2009,2010)$ broader thesis on the influence of neoliberal ideology on popular and institutional interpretations of race and racism. Under such conditions, he argued that:

it is not that race is simply silenced, if silenced at all. It is shifted to less formal domains for the most part, embedded in structures, without being explicitly named, where it is more difficult to identify, more ambivalently related to, more ambiguous (Goldberg, 2010, p. 90).

A consequence of this shift is that, "as race evaporates from the socio-conceptual landscape, racisms (in their plurality) are pushed further and further out of sight, out of "existence", unmentionable because the terms by which to recognize and reference them recede, fade from view and memory" (Goldberg, 2009, p. 36). Yet, crucially, this situation can actually allow racism to flourish, permeating beyond the detection and recognition of the general public (Goldberg, 2010). In this article, I aim to demonstrate that racism remains imbedded within the structures of Western sport, even though certain manifestations may have become increasingly difficult for many observers to recognize. Accordingly, the current analysis explores the enduring presence of covert and subtle forms of racism that occur within the occupational cultures of the professional sporting sphere while acknowledging the advances that have been made in eradicating many of the more blatant articulations of racist discourse and practice.

The focus of this article is English men's first-class cricket and the experiences of British Asian players. Rather than addressing racism in relation to player recruitment and team selection, the investigation centers on racism as discourse-namely, the presence and effects of "racial microaggressions" (Solórzano, 1998; Sue, 2010; Sue, Capodilupo, Torino, Bucceri, Holder, Nadal \& Esquilin, 2007) within player interactions such as locker-room conversations and exchanges during matches. The article not only highlights players' experiences of racism, but also identifies their tendency to downplay the repercussions of some of the forms that this prejudice takes. Accordingly, the marginalization and mitigation of racism is examined from the perspective of recipients, not perpetrators.

This article is divided into five sections. First, it provides some contextual background on racism, and its denial, in English cricket, together with a discussion of British Asian communities in Britain and their participation in this sport. Second, it establishes a theoretical framework introducing racial microaggressions, mitiga- 
tion strategies and the sociological significance of "jokes". Third, the article details the methodology underpinning the study. The fourth section explores empirical data from British Asian first-class cricketers exploring both their experiences, and reflections on the repercussions, of racial microaggressions. In the final section, having identified how these microaggressions are downplayed, I suggest reasons why this response is a prominent one among British Asian players (and minority ethnic elite sportspeople more generally).

\section{Race and English Cricket: The Denial of Racism and the Rise of British Asian Male First-Class Players}

A number of racist episodes can be identified throughout the history of English cricket, ${ }^{1}$ emanating from the game itself, the mass media and certain political figures. These have occurred not only in the domestic setting, but also in external relations with other nations, primarily Pakistan and the West Indies. There are a number of notable examples. In 1990, Conservative MP Norman Tebbit argued that British passport-holders who had migrated from the Indian subcontinent or Caribbean should demonstrate their national loyalty by supporting England, rather than ancestral nations, in cricketing contests. Four years later, writing in the influential Wisden Cricket Monthly, journalist Robert Henderson extended such rhetoric to minority ethnic players, arguing that they did not try as hard as white ones when playing for England and even gained some pleasure from the team's defeats (see Wagg, 2007). Racial stereotyping — both cultural and biological—about minority ethnic players has also been prevalent, including accusations of ball-tampering, cheating, and match-fixing by Pakistani players and officials (Malcolm, Bairner \& Curry, 2010; Williams, 2003) and pejorative comments about Caribbean bowlers' physicality (Williams, 2001). Evidence also highlights discriminatory recruitment and selection policies by some English County Clubs, such as Yorkshire (Williams, 2001), which, despite its proximity to substantial minority ethnic communities, did not field a British Asian player until 2004.

In spite of this history, allegations of racism have frequently been rebuffed by the English cricket establishment, where many individuals refuse to entertain the idea that discrimination exists in the game (Carrington \& McDonald, 2001). Nevertheless, in 1999, the England and Wales Cricket Board (ECB) published its Clean Bowl Racism report. It provided a disturbing picture of the actual extent of discrimination: $58 \%$ of respondents believed that racism existed in cricket; $49 \%$ had "heard of racist actions"; $29 \%$ said they "knew for a fact" that racism existed; $15 \%$ had personally experienced racism; and $28 \%$ knew someone else who had (ECB Racism Study Group, 1999, p. 24). Significantly, more than two-thirds of British Asian respondents believed that racism existed in English cricket (ECB Racism Study Group, 1999, p. 27). The document "conclude[d] that there is a need for positive action as soon as possible and practical against racism that exists in English cricket" (ECB Racism Study Group, 1999, p. 8).

However, while the report issued a challenge to the continuing denial of racism within the game's corridors of power, it has been argued that, in essence, the authorities were simply acknowledging the perception that racism existed rather than the actual practice (Carrington \& McDonald, 2001). In his groundbreaking 
critique of English cricket, Marqusee (1998, p.160) concluded that "racism is not only tolerated but sanctioned by the English cricket authorities." Similarly, Malcolm (2002, p. 317) labeled this reluctance among many within the cricket establishment to engage with problems of discrimination "a conspiracy of silence." Nevertheless, a number of participants in the ECB report believed that racism was no worse in cricket than in other aspects of social life, and that cricket, more than other sports, was best placed to promote positive race relations. This represents a striking example of what Carrington $(2010$, p. 4) termed "the political nature of the apolitical" in sport. He argued that:

it is sport's assumed innocence as a space (in the imagination) and a place (as it physically manifests itself) that is removed from everyday concerns of power, inequality, struggle and ideology, that has, paradoxically, allowed it to be filled with a range of contradictory assumptions that have inevitably spilled back over and into wider society.

In other words, it is precisely the fact that racism is believed to be absent from cricket that allows it to operate in complex, nuanced, and often covert ways.

\section{British Asians and Men's First-Class Cricket}

For those who seek to downplay the existence of racism in sport-including players, coaches, fans, administrators, and the media-the participation of minority ethnic groups at the highest level provides "evidence" that discrimination is no longer a central factor in shaping their opportunities and careers (Abbasi, 2006). British Asian participation in men's first-class cricket has increased significantly in recent years, from only a handful of players in the 1990s to around 30 at the current time. In many ways, this has obfuscated the decline of black British players, whose presence at the highest level has decreased by a similar margin during the same period (Steen, 2004).

As Sayyid (2006, p. 4) points out, "there is a continuing debate about the most appropriate way of describing and labelling those settlers that hail from South Asia." This article uses the term "British Asian" to refer to those British citizens who trace their ancestry to, or who migrated themselves from, the Indian subcontinent. It is acknowledged that this nomenclature is both contested and sometimes applied in an inconsistent manner within the academy and beyond (Burdsey, 2007). Not only is the use and privileging of "British" potentially problematic, but the reference to "Asia" also contrasts markedly with its use in other Western contexts, such as the US, where a broader definition includes people from other parts of the continent as well (Hutnyk, 2000; Kaur \& Kalra, 1996; Sayyid, 2006). Nonetheless, with these reservations, the term "British Asian" is retained here, because it reflects not only broader social trends in self-identification within these communities, but is also the chosen term for the majority of current British Asian first-class cricketers (Burdsey, 2010b).

Although a small South Asian presence in the UK can be traced back over three hundred years (Visram, 2002), the most substantial migrations took place following the partition of India and Pakistan in 1947 with migrants coming primarily from the states of Punjab, Gujarat, and Kashmir, and some years later from Bangladesh. According to the 2001 UK Census, out of a total population of just under 59 million 
people, 1,053,411 identified their ethnicity as Indian, 747,285 as Pakistani and 283,063 as Bangladeshi. Taken as a collective group, British Asians, therefore, represent the largest minority ethnic group in Britain. Over the last half-century, British Asians have made substantial social, economic, and cultural impacts on the UK in fields as diverse as business, film, food, literature, medicine, music, and politics (Ali, Kalra \& Sayyid, 2006). Yet, in the popular imagination, they continue to be perceived through what Hutnyk (2005, p. 348) calls the "exotica-fanatica two-step." He argued that British Asians are:

characterised in a double strategy, either as demons or as exotica, and neither stereotype comes close to an appreciation of the diversity of those under anthropological examination. The double strategy makes Asians either, and both, a people of curious culture - bhangra, spicy food, Bollywood - and a people of fanaticism - Islam, Hindutva, religious extremism.

In other words, alongside the burgeoning consumption of "Asianness" within popular culture lies a continuing tendency to denigrate and discriminate against sections of this population, most notably Muslims who are widely seen as "dangerous" and "disloyal" Others (Abbas, 2005).

In the context of their inroads into other aspects of British popular culture, the marked absence of British Asians from the majority of sports at elite level is striking. Most critical work in the sociology of sport has focused on the absence of British Asians from professional soccer. These contributions have highlighted the anomaly between the high levels of British Asian participation in a recreational capacity and their widespread exclusion from accessing the higher echelons of the game (as players, coaches, and administrators), both for men and women, as well as the persistence of racial discrimination at all levels (e.g., Ahmad, 2011; Burdsey, 2007; Ratna, 2011). Cricket, to some degree, stands out from the broader British sporting landscape: around 30 British Asians are currently playing at first-class level, which means that they are over-represented in comparison with their numbers in the overall population (Peach, 2006). ${ }^{2} \mathrm{~A}$ small number of these players have also played for the England national team (Burdsey, 2010b). The British Asian contingent is supplemented by a number of players of South Asian background from India, Pakistan, Sri Lanka, and South Africa, who are recruited directly as "overseas" players. ${ }^{3}$ Cricket has thus become highly symbolic of wider migratory patterns and changing racial formations in the nations in which it is played. In England, British Asian communities have provided a well-needed challenge to the game's racial hegemony, contributing to more multicultural playing rosters and subverting the ingrained perspective that "Englishness" and "whiteness" are synonymous. In addition to England, the national teams of Australia, New Zealand, South Africa, Canada, and the Netherlands now frequently include South Asian players. ${ }^{4}$

Opportunities for British Asians to reach the highest playing levels (if not those of coaching, management, and governance) do, therefore, exist in cricket. Yet such a superficial reading creates an overly benign portrayal, for numerical representation by no means correlates with feelings of inclusion and belonging, or signifies the eradication of inequality and prejudice. In fact, the small body of sociological research on racism in English cricket has provided substantial evidence of discrimination against minority ethnic players. ${ }^{5}$ The most illuminating examples focus on the recreational level and/or issues related to the England national team. 
This work has identified the multiple forms of prejudice and discrimination that minority ethnic players face such as the denial of access to certain opportunities, venues and facilities; accusations of unsporting behavior; and overt racist abuse as well as the exclusionary effects of the pervasive construction of "Englishness" as a white identity (Carrington, 1998; Carrington \& McDonald, 2001; Fletcher, 2011; McDonald \& Ugra, 1998; Marqusee, 1998; Williams, 2001). These are insightful observations with which this article concurs and they provide important background for the issues discussed here. However, while there are notable exceptions (Burdsey, 2010a, 2010b; Malcolm, 1997, 2001, 2002), there has been little research on race issues within the playing cultures of the men's first-class County game. I aim to address this gap in this article.

\section{Theoretical Background}

St. Louis (2005, p. 129) observed that "the social and cultural meaning of sport is not arbitrary but emergent and contested." This represents a good starting point for understanding sport, and cricket in particular, as an important site for "racial formation", namely the "sociohistorical process by which racial categories are created, inhabited, transformed, and destroyed" (Omi \& Winant, 1994, p. 55). Carrington's (2010, p. 66) notion of sport as a "racial project" is particularly pertinent to the current analysis. This perspective, he argued, entails seeing sport as something "that has effects in changing racial discourse more generally and that therefore reshapes wider social structures. Sports become productive, and not merely receptive, of racial discourse and this discourse has material effects both within sport and beyond". In what follows below, I demonstrate how the cultural positioning, representation, and treatment of young British Asian, especially Muslim, men in English first-class cricket - as the most significant racialized Others-is both product and producer of their representation in wider British society (see also Burdsey 2010a).

This article applies a Critical Race Theory (CRT) (Hylton, 2009, 2010) approach to examine sport, particularly cricket, as "productive" of racism. I fully acknowledge the potential problems of a white scholar taking this standpoint (Bergerson, 2003). As an embryonic theoretical perspective in the sociology of sport, CRT provides a new insight into racial issues in cricket which have thus far been examined through cultural studies (Carrington \& McDonald, 2001), figurational (Malcolm 1997, 2001, 2002), or historical approaches (Williams, 2001). While these accounts have been extremely valuable in mapping racism in the game, a tendency toward macro-analysis and/or historical description has led to an absence of the "voices" of British Asian professional players themselves and, arguably, a failure to explore more subtle and nuanced forms of prejudice and discrimination. This section elucidates how a CRT perspective develops and strengthens these previous investigations, and thus, enhances our understanding of this phenomenon.

Like its view on the role of race within broader social relations, a CRT position on cricket (and sport more generally) develops from an understanding of the commonplace, permanent and complex nature of racism within this arena. As such, the present analysis endorses the claim that "racisms are not unusual or abnormal. To the contrary, racist expressions are normal to our culture, manifest not only in extreme epithets but in insinuations and suggestions, in reasoning and representa- 
tions, in short, in the microexpressions of daily life" (Goldberg, 1997, p. 21). There are three further tenets of CRT that denote its distinct approach to this topic. First, it recognizes the inability of dominant discourses and policies to acknowledge and address manifestations of racism beyond blatant, crude forms of discrimination (Gillborn, 2008). Second, it shows that hegemonic claims of meritocracy, objectivity, and neutrality which permeate sport actually buttress the interests of white groups, and ultimately sustain, rather than eradiate, racial inequalities (Tate, 1997). Finally, CRT provides a theoretical framework to understand the damage that can be inflicted on minority ethnic communities through the speech of dominant groups, by naming the injuries they experience, and identifying and unmasking the origins and repercussions of this harm (Matsuda, Lawrence, Delgado \& Crenshaw, 1993).

It is important to point out that CRT was developed to analyze the cultural context for racism in the United States. In particular, it emerged in response to a relatively context-specific configuration of dominant ideology, racial formation, institutional discrimination, and antiracist mobilizations. Having grown out of developments in critical legal studies (and later education), primarily as a critique of the ethnocentric focus of this discipline (Delgado \& Stefancic, 2001), its roots are embedded within African-American, American Indian, Latina/Latino, and Asian American social thought (Parker \& Lynn, 2002). It is, then, inexorably a product of a distinctly American sociopolitical milieu embedded in the history of Civil Rights and race relations, as well as the particular ethno-racial groups, divisions, and hierarchies in the US. Consequently, the analytical power of CRT might be questionable in the British context (Banton, 2011; Pitcher, 2011).

However, as Gillborn (2008, p. 1) pointed out, "to date, CRT has remained an almost exclusively American approach but there is no reason why the conceptual tools and techniques developed by critical race scholars elsewhere cannot be adopted and refined through their application in other nation states" (see also Gillborn, 2011). This interpretation of CRT's global relevance and application is employed here by emphasizing the theory's inclusive and transdisciplinary nature. It is neither a unified nor homogenous school of thought, as evidenced, for example, by the development of Lat/Crit and critical race feminism. Consequently, if it can transcend disciplinary and, to some extent, methodological boundaries, then arguably contextual ones should (where appropriate) also be traversed, for theoretical stasis is not conducive to CRT's analytical and emancipatory capacities. As Pitcher (2011, p. 204) argued, CRT "has the potential to be attentive to the historical and cultural specificity of racisms (in the plural) and does not claim to possess a theory of race that is universal and unpatterned by the contingencies of time and space." More specifically, Hylton (2009, p. 34) stated that it is important to move beyond the parochial nature of some race theorizing, and sport and leisure scholars "should be wary of utilising a familiar and/or narrow multidisciplinary straightjacket that might constrain them in explaining modern (or historical) phenomena." To be clear, while acknowledging that its usage may not be entirely global in scope, I argue here that by embedding multiple disciplinary and methodological approaches CRT is not limited to one cultural milieu. Its emphasis on the nuanced relationship between racialized structures, ideologies, and discourses provides valuable theoretical and methodological tools for analyzing contemporary racisms in a range of Western, neoliberal contexts. ${ }^{6}$ This is particularly the case with sport where, in the UK at least, a "color-blind" approach is increasingly evident (Lusted, 2009). 
I draw here from Bonilla-Silva's (2006) seminal work on the concept of "colorblind racism." He uses this framework to explain how, despite the advances made by the Civil Rights movement, together with widespread contemporary avowals that racism is no longer an issue, racial inequality remains systemic in twenty-first century US society. The four frames of color-blind racism he identifies are abstract liberalism, naturalization, cultural racism, and minimization of racism. Abstract liberalism refers to the manner in which racial inequality is justified on the basis of an individual's right to choose. To use a sporting example, liberal principles are used to defend racially-segregated sports leagues, with the absence of minority ethnic participants from many mainstream settings interpreted as a desire to compete among one's own community rather than the result of exclusionary attitudes and practices. The second frame describes the way that racial phenomena are explained by the belief that they are natural occurrences, while the third addresses the shift toward cultural attributes, rather than biological ones, within contemporary racist discourses. Of most significance for this article is the "minimization of racism" frame. This frame not only posits that prejudicial views and behavior are no longer a major factor affecting the life chances of minorities, but by also viewing discrimination as synonymous with blatant, full-on racist instances it "eliminates the bulk of racially motivated actions by individual whites and institutions by fiat" (Bonilla-Silva, p.30).

Two other concepts are used in this article. Neither is exclusive to a CRT approach, but they provide important tools for such an analysis. The first is "racial microaggressions". These are "brief, everyday exchanges that send denigrating messages to people of color because they belong to a racial minority group" (Sue, Capodilupo, Torino, Bucceri, Holder, Nadal \& Esquilin, 2007, p. 273). Key to the transmission of microaggressions is the fact that they can often be subtle and unconscious, and they may also manifest themselves in gestures, looks, or tones. A solitary microaggression can have some degree of impact, but their accumulation over a period of time can have more significant detrimental consequences. Their repercussions are not limited to the individual, psychological level, but can also affect groups' life quality and opportunities within a given social sphere (Sue, 2010). In some spheres, microaggressions are so pervasive that they are often dismissed by members of the dominant group as insignificant and harmless. As a result, they represent an important component of the minimization of racism frame. ${ }^{7}$

The second concept is "mitigation strategies." These refer to the processes through which individuals seek simultaneously to downplay or deny incidences of racism and to exonerate those accused of engaging in such acts (whether that be themselves or others). This involves offering alternative explanations with the purpose of refuting intentionality and responsibility on the part of the person(s) under scrutiny (van Dijk, 1992). Doane (2006, p. 259) stated that these strategies of denial are integral components of the "color-blind" frame, as:

given the general social consensus that racism violates social norms and the strong negative valuation attached to the "racist" label, charges of racism are a significant rhetorical and political weapon. In the twenty-first century, no one wants to be accused of racism or to be called a racist (Doane, 2006, p. 260).

Although they can take many forms, including downright claims that racism has not been committed or that an individual is not a racist, mitigation strategies often work in much more subtle ways. As van Dijk (1992, p. 92) suggested, pro- 
cesses of mitigation include "downtoning, minimizing or using euphemisms when describing one's negative actions." These often reproduce what Feagin and Vera (1995) labeled "sincere fictions:" processes through which individuals both employ a view of society that denies the existence of racism and position themselves as not possessing any form of prejudice, yet simultaneously engage in behaviors that reproduce racial stereotypes and maintain inequalities. These mitigating strategies have been identified in a variety of sporting settings. ${ }^{8}$ Indeed, because antiracismat the level of rhetoric, if not in terms of adopting meaningful antidiscriminatory measures (see Hylton, 2010)_-is so ensconced in sport, mitigation takes on a crucial role. As van Dijk (1992, p. 92) argued, "we may assume that the more stringent the norm against discrimination and racism, the more people will tend to have recourse to denials and hence also to mitigations."

One way in which individuals seek to avoid or mitigate accusations of racism is to claim that their comments were merely banter or "just a joke" (Billig, 2001; Matsuda, Lawrence, Delgado \& Crenshaw, 1993; Picca \& Feagin, 2007). It is commonly perceived that jokes are different to "serious" discourse and should be viewed through an alternative schema of interpretation (Pickering \& Lockyer, 2009). The upshot of this is that "humour at once permits, legitimates and exonerates an insult, whether this is through comic parody, impersonation or two-way badinage. The joke or comic discourse allows the contraband cargo of the offence to be smuggled aboard" (Pickering \& Lockyer, 2009, p. 14). For instance, in their study of Dutch soccer, Müller, van Zoonen and de Roode (2007, p. 341) discovered that "in many cases processes of Racialization were simply not immediately recognized [by participants] as such because they occurred in the context of friendly and joking interactions." Through claiming that a racist comment is "just a joke," the teller, therefore, constructs her/himself not just as not trying to cause offense, but more importantly, as not really racist. Crucially, recipients can also buy into this dominant interpretative frame, not only by holding similar views about what constitutes "humorous" discourse and reinforcing binary racist/not racist models, but also through their desire not to be seen as unable to take a joke or perceived as too "politically correct" (Pickering \& Lockyer, 2009).

In summary, a CRT approach to understanding racial microaggressions, mitigation strategies and, specifically, the use of jokes facilitates a richer, more informed analysis of racism in cricket. CRT's emphasis on challenging dominant discourses and policies to acknowledge and address manifestations of racism beyond blatant, crude forms, together with an understanding of the damage that can be done through ostensibly benign, jocular speech, enables a timely and critical appraisal of the enduring specter of race in the English game.

\section{Methodology}

The empirical material for this article was generated through interviews with twelve British Asian professional cricketers during 2008. Although this represents a relatively small sample group, it corresponds to nearly half the total number of players who comprise this category in the domestic game. The semistructured interview method-discussing themes and topics rather than asking set questions-complemented the CRT theoretical framework, particularly its emphasis on centering marginalized voices, because it allowed participants to emphasize those issues that they believed to be important (Arksey \& Knight, 1999). The majority of 
players in the sample (and among British Asian first-class cricketers in general) are of Pakistani background and are Muslims. Any suggestion that there is a singular British Asian experience in the professional game is, however, inaccurate. There are a range of experiences differentiated not only by ethnicity, religion, and family history, but also by aspects of class, age, location and the vicissitudes of sporting careers (Burdsey, 2010b).

Participants were identified via a systematic search of clubs' official websites. Formal letters were sent to all clubs, explaining the study and requesting permission to speak to their players. Following a degree of success with this method, a network or "snowball" sampling technique (Bloch, 2004) based on contact information provided by players themselves was used to expand the participant base. Players were informed fully about the project's rationale, objectives, content, and proposed dissemination, via initial e-mail and/or telephone communication, and verbal consent was again sought before the interviews commenced. It was made clear to participants that the study aimed to investigate their lives as British Asian elite players, focusing on issues related to their identities, experiences of discrimination, and the wider sociopolitical context in which they played, rather than their cricketing careers per se. Interviews were undertaken in players' homes, cafés, hotels or club grounds. These were taped on a digital voice recorder and transcribed as soon as possible afterward. To maintain anonymity, the names of players and clubs, as well as distinguishing features and achievements, have been removed from the text.

As is well-known to sport sociologists, research in the field of race and ethnicity is replete with methodological and epistemological conundrums. This project was no exception, with recognition of enduring issues relating to power relationships between white researchers and minority ethnic participants, and "outsider" analyses of racism, framing the design, fieldwork and analysis. ${ }^{9}$ In addition, it was imperative to be aware of the potential adverse effects of writing about young British Asian, particularly Muslim, men, as even well-meaning social science research can inadvertently reinforce, rather than challenge, stereotypes and the demonization of these groups. Notwithstanding this, the research proceeds from the contention that those of us who share a racial identity - but not a political or ideological one-with those who continue to deny racism have an important role to play. As Wise (2009, pp. 118-9) states, in addressing those who refuse to listen to minority accounts of the personal and structural manifestations of racism, "if whites will not listen to voices from black and brown communities, then fine, they will have to hear it from their own" (see also Delgado, 1997).

It should be noted that this article does not make general claims about the existence of racism in cricket. This is an impossible task for a single, smallscale study and a reliance on interview data. The more modest aim is to take the examples of racial microaggressions discussed by participants, and analyze the methods and explanations they employed to mitigate them. In terms of antiracism as a political, as well as academic, project, it might be argued that addressing the denial of racism among majority white groups is actually more important and that highlighting minority refutations could actually play into the hands of the very agendas that are being opposed. However, the appropriation of color-blind rhetoric by minority ethnic groups both highlights the pervasiveness of the discourse and illuminates the restrictions around talking about race placed on players from these communities (Bell, 1992). 


\section{British Asian Cricketers' Accounts and Interpretations of Racial Microaggressions}

The interviewed players recalled discriminatory incidents when interacting with other players (and occasionally supporters) including locker-room conversations and exchanges during matches, but rarely mentioned such incidents in professional recruitment and selection processes. Some players reported specific forms of microaggression that can be classified as "microassaults". These are "explicit racial derogation[s] characterized primarily by a verbal or nonverbal attack meant to hurt the intended victim through name-calling, avoidant behavior, or purposeful discriminatory actions" (Sue, Capodilupo, Torino, Bucceri, Holder, Nadal, \& Esquilin, 2007, p. 274). As Player 1 recalled:

I've heard instances of players being racially abused. Yeah, it's not come out into the open. One of the umpires or the player himself has said, "I don't want to make a big issue about it" or, you know, the umpires and the captains have got together and quashed a situation and given someone a slap on the wrist and a word in their ear.

He added that:

They don't want to make an issue of it just in case it blows out of proportion, so a lot of it is then just quashed and, you know, pushed aside.

Player 2 spoke about the following examples:

Oh, just words like "Pakis" and stuff like that. I think the thing [this player] always said to me was, "Come on boys, let's get this Paki out". That's what I've heard. Other than that, yeah, I just ignored him to be honest.

I think it was three years ago, after [the London terror attacks]. When I played in club games, yeah. I had a few comments. Well, it was one of my team-mates. They were making jokes, you know, [calling me a] "bomber" and that.

In a similar vein Player 3 stated that:

I went to Australia after I left university to play cricket for six months. On my "coffin" [the large wooden case used to carry playing equipment] I had a sponsor from Haman's cricket suppliers, based in [city], and the Australian chap said to me, "Are you part of Hamas?". ${ }^{10}$ I said to him, "What makes you say that?", and he said, "On your coffin it says Hamas". I said, "No, if you read it properly it says Haman's". It's gold writing on a blue coffin so you can clearly see it.

This player went on to contextualize such comments within rising Islamophobia in wider society and to highlight how this has also affected the content of racist discourses in cricket:

Whatever's happened in the last couple of years, I think it's diverted the effects of racism to a direct effect. As opposed to, I mean, something like being called a "Paki" or being called a "black bastard", you would then be called "a bomber" or be discriminated against by saying, "Where's your backpack?" or something like that. 
The testimonies of this player and Player 2 reinforce the arguments raised earlier in this article about the significance of cricket as a dynamic site for racial formation, with racial categorizations in sport underpinned by (and underpinning) broader sociopolitical trends.

Player 6 also highlighted a particular shift in behavior, but one that referred instead to the effects of fame and status on other people's attitudes:

[That player is a] very good friend of mine and I've known the things he went through. Now he's [an international], the same people are asking for his shirt and his autograph, you know, the same people that criticized him, gave him racial abuse sort of thing.

Other players recalled experiences of "microinsults." These are "communications that convey rudeness and insensitivity and demean a person's racial heritage or identity" (Sue, Capodilupo, Torino, Bucceri, Holder, Nadal, \& Esquilin, 2007, p. 274). For instance, participants spoke of receiving negative comments about the Islamic male practice of wearing a long beard, and South Asian family structures and living arrangements:

The crowd, more than anything, get on my back a bit when I'm fielding. They don't say anything like "terrorist", they just say, "You're head's upside down". [Player 5]

[My team-mate] has actually got a beard. At [our club] it's fine, but you go to different Counties and different supporters, and they're actually calling you names. That was actually quite a big thing. I was actually getting upset. [He] was fine with it, but I was getting angry because he's my [team-mate]. I actually wanted to throw the ball at [the supporters] because we were fielding nearby. I could have easily picked up the ball and chucked it. [I could have said] "Oh, it slipped out of my hand, sorry". I was getting really annoyed as it was blatantly rude. "So what if he's got a beard. He's here to play the game of cricket, you've paid to watch the game of cricket, so why call him names?". [Player 6]

There's clubs that always ask the Asian kids about their religion: "Why are you still with your parents when you're twenty-five?"...I understand how it's quite hard for people, but sometimes I feel they try to make you feel quite bad about still living with your parents...Some players actually know about our family values, but they'll just keep asking you questions about it, so you actually can feel like a muppet ${ }^{11}$ sometimes in front of them. [Player 6]

What is especially significant about the testimonies of the players in this research is that alongside stressing the gravity and repercussions of racism in some contexts (above), they also demonstrated a tendency to downplay its seriousness and consequences in other scenarios. For example:

One of my team-mates, they were making jokes, you know, "bomber" or that, but I just took it as a joke and moved on really. I didn't take it serious... Yeah, you get odd jokes, but that's it really. [Player 2] 
I don't think [team-mate] was purposefully being racist, he was having a crack and a joke. Obviously I have been around the cricket environment long enough to know that some people will have a crack and a joke with you. [Player 3]

You do sometimes get a little bit of banter in the changing rooms, but nothing like, no hatred in that, just a little banter here and there...very light-hearted and nothing serious if you know what I mean. Just jokes here and there. That's it. [Player 7]

I mean, if it's banter, it's a joke. If it's a joke, it's just sense of humor. If it's sense of humor, it's just mainly between good friends. [Player 8]

Some players were even more precise in distinguishing which types of interaction or comment they believed were acceptable and which were not, although the justification they used for tolerating certain types of speech was identical to that outlined above:

Each player will have a different boundary and different limits, and each team that he plays for is different. Every dressing room you go into is different. I played at [County Club A] and almost there was, like, anyone said anything to anyone that's not necessary, well, you know, we had a situation. Whereas at [County Club B] you could say anything to anyone and it's just a laugh and a joke, it's just blown over. [Player 1]

You can't make them kind of [overt racist comments]. I'm not saying you can't joke around. There's always like a couple of racist jokes flying around, but you just take that as a joke. [Player 6]

That's banter, it's like having a laugh. That's - I'm not going to tell you what they have been saying - but that's on a jokey level. That's the relationship I've got with people, you know, take the piss, but that's not meant. You know when something's meant, but that's not meant. [Player 9]

These testimonies reinforce the theoretical argument raised earlier in this article that a key strategy in mitigating the effects of racist comments is to locate them within playful, jocular discourses. Yet jokes can underpin divisive and exclusionary aspects of sporting subcultures, and they represent a powerful and symbolic means by which minorities are marginalized from dominant player collectives. Indeed, they have been a prominent way in which Asians in general have historically been effaced and defaced in Western sport (King, 2006).

Of course, there are different types of jokes. They can be affectionate, malicious, or somewhere in-between and are often "intentionally ambiguous" (Jimerson, 2001, p. 335). It has also been argued that much of the off-field "talk" that goes on in sporting contexts should not be taken too seriously. For instance, Curry (1991, p. 133) argued that:

on the one hand, behavior in locker rooms is both ephemeral and situational and probably does not reflect the actual values of all participants. From this perspective, the locker room is just a place to change clothing and to shower, and one should not make too much of what goes on there. 
Furthermore, Jimerson (2001, p. 336) questioned an outsider's ability to appreciate fully the context in which comments are made and to gauge the intentions of the perpetrator(s), arguing that "what people see depends on where they stand. This is as true for sociologists as it is for those whom we study. Therefore we would do well to let our subjects' interpretations inform our own." Based on Jimerson's skepticism, the following testimony from Player 1 could be interpreted in several ways:

The term we used, you know, at [my previous club] was "curry munchers". I've never seen that as, you know, a racist thing...We used it about Asian players as well, on other teams and other, you know, just locals, or when we were walking down the street. "Go on, the munchers!'...It was something that came from the Asian players, so it wasn't a label that got given to them. It was something we did and I didn't see that as racist.

All individuals construct their own parameters of acceptability, which may, in turn, be driven by wider structural forces. This player deems that because the phrase "curry munchers" was generated by British Asian players themselves it is not offensive to him or his British Asian team-mates. Indeed, as Billig (2009, pp. 33-4) points out, "sometimes when an insider tells a joke that repeats conventional stereotypes, the joke can be understood as mocking stereotyping and prejudice" (see also Weaver, 2010). ${ }^{12}$ To discount participants' organic knowledge and capacity to interpret social phenomena displays an academic arrogance unsuited to the establishmnent of sophisticated analyses and empowering research protocols. As Clarke and Garner (2010, p. 189) warned, "if we do not take our subjects" narrative on face value then surely we are just imposing our preconceptions on the data, our "findings" could just be wild analysis, which the researcher needs to be aware of."

However, even though research participants might state that they do not believe they have been the recipients of racism, this does not necessarily mean that racist acts have not taken place (Long \& McNamee, 2004). Based on this reasoning, Player 1's proposal of such a clear correlation between intention and outcome, and "ownership" of the discourse, is possibly too simplistic. Irrespective of creation and intent, an act or comment can have racist repercussions. In this instance, a CRT analysis offers an alternative interpretation to the standpoint observation of the individuals who are actually party to the joke. As Robidoux (2001, p. 131) argued:

to understand the power of the word, we must, at least temporarily, remove the word from the speaker and consider its associated network of meanings. The illocutionary force of the speech act must be placed in a larger historical context rather than viewed merely as the product of the will of the speaker.

Billig (2009, p. 34) likewise highlighted the importance of context in analyzing jokes, pointing out that this "does not necessarily refer to the immediate person-toperson context in which a joke is told. It can also refer to a more general ideological or political context that can affect the meaning and understanding of a joke." Like any form of racial discourse, jokes are therefore a matter of power relations, contingent upon the identities of the instigator, recipient, and audience. Thus, the context in which it is articulated and the way that it is subsequently reproduced by 
dominant groups within the club mean that the "curry muncher" term may not be as innocent as Player 1 portrays.

Dismissing incidents as "jokes" and claiming "ownership" of a discourse were not the only mitigation strategies employed by players. For example, Player 2 proposed that it was his inclusion and success in the teams he has represented that negated the possibility of racism:

I didn't take [the comments] serious. At the end of the day obviously they wanted me to play for them, that club. It was a really good club. I'm playing at the moment, and they do want me to play for them. Obviously they don't want to lose me.

Alternatively, Player 10 perceived banter to be a give-and-take relationship, involving, and directed at, all players within a club, irrespective of their background. Comments about one's ethnicity or religion were thus seen as no worse than others:

It's a bit of banter...me and [British Asian team-mate] take it pretty well and we give a bit back, so I think you have to take a bit and give a bit, and I think that will be the peace, if you understand what I am trying to say...So it's never been racism.

In addition, Player 1 downplayed the racial component of comments by arguing that they were instead actually cultural references:

I think there's a barrier, there's a line. I've been called, you know, a "Paki" by a team-mate. For me, that's not a racial thingy. I didn't see that as, you know, you're saying it because you're saying it against the color of my skin. It was more of a cultural thing.

The most significant feature of both these latter approaches is ultimately their ability to elide the context behind, and power dynamics underpinning, racial discourse, thus obscuring the factors that make such comments more serious and problematic than other forms of banter.

Bonilla-Silva (2006) pointed out that racism is rarely minimized by minority ethnic groups. Nonetheless, although minimization was clearly not employed as a universal strategy in the testimonies cited in this article, it was certainly evident in particular contexts. While many British Asian players reported incidents of racism which they classified as deliberate and serious, they also recalled "jokes" that were perceived as unintentional and thus meaningless. The findings of this study, therefore, support Bonilla-Silva's (2006, p.172) claim that color-blind ideology is not simply reproduced by white groups, but also sometimes by the "many slightly color-blind blacks." As in other social spheres, it is apparent that while marginalized groups are able to construct oppositional perspectives, "it would be foolish to believe that those who rule a society do not have the power to at least color (pun intended) the views of the ruled" (Bonilla-Silva, 2006, p.10). In other words, color-blind ideology is so entrenched in Western sport that minority ethnic participants, as well as those of dominant racial groups, can at times endorse its interpretive framework. 


\section{Minority Ethnic (Non)responses to Racial Microaggressions}

The findings here correspond to Sue's (2010) "Catch 22" situation facing minority ethnic recipients. He stated that the "most frequent reaction to microaggressions seems to be doing nothing" (2010, p. 55). For instance, Player 1 stated that:

There's not a lot you can do about it to be honest with you, you know...you ignore it because you become almost deaf to what people are saying.

Researchers have identified a number of reasons why this might be the case.

First, the individual might be unable to establish if a microaggression has occurred. They are often ambiguous and thus harder to identify and categorize than overt, obvious acts of racism. Indeed, it can be the "invisibility" of microaggressions to the recipient and often also the perpetrator that makes them so powerful (Sue, Capodilupo, Torino, Bucceri, Holder, Nadal \& Esquilin, 2007). The fact that the comments discussed here are "masked" within the context of locker-room banter can also increase the difficulty in detecting, and responding to, them. A related trend within contemporary racist discourses is the "coded" nature of certain forms of speech. This entails the use of particular terminology that draws on referents from cultural stereotypes or topical issues rather than commonly-acknowledged "hate words." These "are terms that convey a racial sensibility but generally are not as quickly recognized or criticized as being "racist'" (Hartigan, 2010, p. 28). As Goldberg (1997, pp. 20-1) argued:

expressions of hate encourage their dismissal as abnormal, not the sort of undertaking ordinary people usually engage in, the irrational product of warped minds. This reduces all racist expression to a single form: what is not reducible to hate is not criminalizable; perhaps it is not even racist (or sexist), for it fails to fall under the reductive characterization of racism (or sexism) as hate.

Second, individuals might believe that a microaggression did not take place, and try to deny its presence, intent or meaning (Sue, 2010). For example, Player 1 stated:

The way it's said, that's when you start thinking, "Was that racist or was it not racist?". 'Cos he's not, ah, he wouldn't say that. 'Cos he's eating dinner with me every day, if he was a racist, you know, he wouldn't be sitting next to me every bloody game, changing with me every day. Surely, you know, he would have had an issue going out with me in the evening?

According to Sue (2010), such denials are often underpinned by a couple of key factors. The recipient may have a close relationship and/or regular interaction with the perpetrator. In this instance, the players train and play together every day. In addition, the participant might not want to acknowledge what the act could infer-that their team-mate/friend harbors racist views and that they are seen in a negative manner by others. Sport can further accentuate the tendency to deny racism. As Brown, Jackson, Brown, Sellers, Keiper and Manuel (2003, p. 165) pointed out, "racially and ethnically diverse athletic teams train, travel, compete, and win or lose together. That is, goal-oriented interracial interaction on sport teams 
can lead to reduction of racial distinctiveness and downplaying of racial division for some athletes". 13

The third reason for nonresponses to microaggressions is that individuals may feel powerless to react to them, believing that speaking out either will have little impact or is risky (Sue, 2010). For example, studies have highlighted the perception among some minority ethnic sportspeople that there is often little point in reporting racism because it will not be taken seriously by clubs and the authorities, and perpetrators will likely go unpunished (Burdsey, 2004; King, 2004). As van Dijk (1992, p. 96) pointed out, "when the dominant consensus is that there is no racism, minority groups and their protests or other forms of resistance have a very hard time to be taken seriously." Individuals who speak out are routinely accused of "playing the race card", yet in actual fact "precisely because white denial has long trumped claims of racism, people of color tend to underreport their experiences with racial bias, rather than exaggerate them" (Wise, 2008, p. 28). For example, Player 2 situated his experiences not simply in cricket, but within the broader racial politics of contemporary Britain:

Because I'm living in a white country, obviously I'm going to get [racism]. I know that. So I've just got to take it as a joke and move on.

Some recipients of racism may also be fearful of the consequences of speaking out due to the danger of being marked as "risky bodies" (Puwar, 2005, p. 53). For example, research on soccer shows that players who speak out against discrimination, or discuss race outside the terms of the dominant discourse, can be labeled "trouble-makers" and subsequently not accepted as "one of the lads" (Burdsey, 2004; King, 2004). This scenario represents Bell's (1992) "rules of racial standing." He outlined how, despite their experiences, statements from minority ethnic people about racism are seen to be special pleading and not given serious consideration. Conversely, individuals that refute claims of racism made by others receive enhanced status and can gain inclusion within a given institution or sphere. However, Player 1's comments do offer some hope for a conducive climate where challenges to racism in English men's first-class cricket may gradually be created:

As you get more senior, more confident within the team, you get, you know, less worried about saying it, and that's again because there's more Asians in the game, you know, the more confident you feel about questioning these players, especially when [British Asians] are becoming more senior within teams.

\section{Concluding Remarks}

This article has demonstrated that color-blind ideology is so entrenched and pervasive in contemporary Western sport (Leonard, 2004) that its (re)production is not exclusively the preserve of white groups. In fact, it has the capacity to compel minority ethnic participants at times to endorse dominant claims that the effects of racism are overstated as well. As a consequence they can be pressured into denying or downplaying those forms of verbal discrimination which are articulated between team-mates and in a seemingly playful manner, dismissing incidents as merely "banter" or "jokes." Yet contrary to their perceived innocent, playful nature, 
jokes represent a significant means of subjugating racialized groups in sport. Not only do they contribute to the marginalization of minority ethnic participants, the normalization of discriminatory practices and the maintenance of white privilege, but crucially they can also be articulated without being seen to contravene the widespread opposition to racism that exists in this sphere. Furthermore, the perception that racial banter is permissible if undertaken in specific spaces and contexts, and if all comments remain within certain parameters, creates an interpretation of racism as spontaneous, isolated and overt, thus downplaying its structural effects. The focus is shifted from the perpetrator to the recipient, who is subsequently encouraged, or even forced, to dismiss speech or acts that do not go beyond the "boundaries of acceptability." Yet these boundaries are not set by consensus. They are constructed and managed by the dominant group. Ultimately a "tolerance zone" is created in which certain forms of racism are trivialized or ignored, and particular epithets or actions are exonerated.

In a broader sense, this article has attempted to contribute to a developing corpus of sport sociology scholarship that has problematized popular conceptualizations of racism (e.g., Fleming \& Jones, 2007; Long \& McNamee, 2004). While common interpretations over-simplify its contents and posit that its "presence" or "absence" can be straightforwardly and unequivocally established, I have argued for the need to map different gradations of racism, and to explore issues around intent, reception, and context. In this regard, the hegemonic model of oppositional categories "racist" and "not racist" is inadequate. There are two main reasons for this. First, the model does not provide a sufficiently sophisticated framework for mapping the trajectories and ramifications of contemporary racisms, as acts or comments are not recognized and classified as racism unless they are deemed to be intentional and/or obvious (Trepagnier, 2006). Second, in a practical, political sense, the model does not represent an effective way of challenging racism. In fact, due to its narrow conceptual schema of what racism is and/or does, it actually facilitates the dismissal and exculpation of racist acts. As this article has demonstrated, CRT helps us progress beyond dichotomous racist/not racist interpretations. By identifying the potentially racist components and repercussions of acts that are not necessarily blatant, intentional, or involving hate words, the analysis has highlighted the ambiguity that can both arise from what people say and characterize their interpretations of racism. As such, CRT points to the misguided and futile task of trying to establish definite categorizations.

To return to the sentiments raised at the beginning of this article, it is certainly difficult to contest the argument that, with the growth of antiracism, the capacity and support for speaking out against racial discrimination in British sport is the greatest it has ever been. However, this viewpoint overestimates the influence that this movement has had on bringing structural change. Public stands against racism by clubs and governing bodies are a central facet of contemporary professional sport, yet their targets are often nebulous and generic in nature. Identifying and reporting specific, individual racist comments, acts, and behaviors among playing, administrative, and coaching personnel requires an acknowledgment that racism exists at the center of sport not at its periphery. This might require some concrete action rather than vague promises (Hylton 2010) with which professional sport is still largely extremely uncomfortable. Despite the everyday claims made about sport's integrative potential, an exposition of manifestations of racial microagres- 
sions and the effects of color-blind ideology in English men's first-class cricket shows that the struggle for racial equality is far from over.

\section{Notes}

1. The term "English cricket" is used because, while the game is played throughout the UK, all but one of the first-class County Clubs are from England. Furthermore, England is the only UK nation to play first-class Test cricket.

2. A South Asian presence in English cricket can be traced back to Indian player Kumar Shri "Ranji" Ranjitsinhji in the late nineteenth century. It has burgeoned in a number of "phases" throughout the last century: the recruitment of Indian and Pakistani internationals at County Clubs during the 1970s; the breakthrough of second-generation British Asians during the 1990s; and the current state of affairs.

3. It is difficult to provide a total number of male first-class cricketers in England, but with 18 Counties playing an 11-a-side game, an estimation might be made at around the 400 mark.

4. This state of affairs is also arguably part of a process that Rumford (2007) labels "post-Westernization". This refers to a shift in the balance of power within cricket administration toward Asian nations, demonstrated by, for example, the International Cricket Council (ICC)'s relocation from London to Dubai, the introduction of the Indian Premier League and the growing significance of limited-overs cricket in relation to five-day Test matches.

5. Although this article focuses exclusively on the experiences of British Asians-by far the numerically dominant minority ethnic group in English first-class cricket-it is important to recognize that African-Caribbean players have also historically experienced racism (see Williams, 2001 for details).

6. See Salmi (2011) for an application of CRT in the French context.

7. Although the concept of microaggressions per se is extremely useful for the phenomena being explored here, the wording itself could be considered misleading. If anything, many racist acts are undertaken in a way that is far from aggressive- one of the reasons why they often go under the radar of detection and remain unchallenged.

8. Examples include spectators' treatment of African-American tennis players Venus and Serena Williams (Spencer, 2004), recruitment practices in English professional soccer (Burdsey, 2007), youth baseball in the US (Glover, 2007), fan behavior in Dutch soccer (Müller, van Zoonen \& de Roode, 2007) and the reception of race equality initiatives in English amateur soccer (Lusted, 2009).

9. There is space in this article to provide only a relatively succinct overview of the research process, and a much more comprehensive exploration of, and reflection on, the factors pertaining to this project can be found elsewhere (see Burdsey, 2010a).

10. Hamas is a Palestinian organization that aims to establish an Islamic state in the Gaza Strip and West Bank.

11. Derived from Jim Henson's acclaimed The Muppet Show in the US, the term "muppet" is used in the British context as a form of slang to refer to someone undertaking stupid or foolish behavior, or getting something wrong.

12. There is evidence of ostensibly discriminatory terms about South Asian and Arab groups being used in a subversive way, or "reverse" manner, in other sporting contexts. Thangaraj (2010), for example, discusses the proclivity for South Asian basketball teams in the US to adopt team names such as Camel Jockeys, Sand Brothaz and Atlanta Outkasts.

13. See Long (2000) for an in-depth account of why elite participants might deny the existence of racism in sport. 


\section{Acknowledgments}

This research was funded by a British Academy Small Grant entitled "The experiences of British Asian players in contemporary county cricket: ethnicity, identity, racism" [SG-46858]. Earlier versions of this article were presented at the North American Society for the Sociology of Sport Annual Conference (Denver, November 2008) and the British Sociological Association Annual Conference (Cardiff, April 2009). I am extremely grateful to: the editors of SSJ, the two anonymous reviewers and Thomas Carter for their constructive and supportive feedback on earlier drafts; Denise Scott Fears and Julia Lansdowne for transcribing the interviews; and Christine Dallaire for introducing me to the literature on sports locker-room talk.

\section{References}

Abbas, T. (Ed.). (2005). Muslim Britain: Communities under pressure. London: Zed Books. Abbasi, K. (2006). East is east. Wisden Cricketer, 3(12).

Ahmad, A. (2011). British Muslim female experiences in football: Islam, identity and the hijab. In D. Burdsey (Ed.) Race, ethnicity and football: Persisting debates and emergent issues (pp. 101-116). Abingdon: Routledge.

Ali, N., Kalra, V.S., \& Sayyid, S. (Eds.). (2005). A postcolonial people: South Asians in Britain. London: Hurst.

Arksey, H., \& Knight, P. (1999). Interviewing for social scientists. London: Sage.

Banton, M. (2011). The sociological implications of demographic diversity. In K. Hylton, A. Pilkington, P. Warmington, \& S. Housee (Eds.), Atlantic crossings: International dialogues on Critical Race Theory (pp. 154-175). Birmingham: C-SAP.

Bell, D. (1992). Faces at the bottom of the well: The permanence of racism. New York: Basic Books.

Bergerson, A. (2003). Critical Race Theory and white racism: Is there room for white scholars in fighting racism in education? International Journal of Qualitative Studies in Education, 16(1), 51-63.

Billig, M. (2001). Humour and hatred: The racist jokes of the Ku Klux Klan. Discourse \& Society, 12(3), 267-289.

Billig, M. (2009). Violent racist jokes. In S. Lockyer \& M. Pickering (Eds.), Beyond a joke: The limits of humour (pp. 27-46). Basingstoke: Palgrave.

Bloch, A. (2004). Doing social surveys. In C. Seale (Ed.), Researching society and culture (2nd ed., pp. 163-178). London: Sage.

Bonilla-Silva, E. (2006). Racism without racists: Color-blind racism and the persistence of racial equality in the United States. Oxford: Rowman and Littlefield.

Brown, T., Jackson, J., Brown, K., Sellers, R., Keiper, S., \& Manuel, W. (2003). 'There's no race on the playing field': Perceptions of racial discrimination among white and black athletes. Journal of Sport and Social Issues, 27(2), 162-183.

Burdsey, D. (2004). 'One of the lads'?: Dual ethnicity and assimilated ethnicities in the careers of British Asian professional footballers. Ethnic and Racial Studies, 27(5), 757-779.

Burdsey, D. (2007). British Asians and football: Culture, identity, exclusion. Abingdon. Routledge.

Burdsey, D. (2010a). British Muslim experiences in English first-class cricket. International Review for the Sociology of Sport, 45(3), 315-334.

Burdsey, D. (2010b). Midnight's grandchildren at the MCC: British Asians, identity and English first-class cricket. In C. Rumford \& S. Wagg (Eds.), Cricket and globalization (pp. 252-269). Newcastle upon Tyne: Cambridge Scholars Publishing.

Carrington, B. (1998). Sport, masculinity and black cultural resistance. Journal of Sport and Social Issues, 22(3), 275-298. 
Carrington, B. (2010). Race, sport and politics: The sporting black diaspora. London: Sage.

Carrington, B., \& McDonald, I. (2001). Whose game is it anyway? Racism in local league cricket. In B. Carrington \& I. McDonald (Eds.) 'Race', sport and British society (4969). London: Routledge.

Clarke, S., \& Garner, S. (2010). White identities: A critical sociological approach. London: Pluto Press.

Curry, T. (1991). Fraternal bonding in the locker room: A profeminist analysis of talk about competition and women. Sociology of Sport Journal, 8, 119-135.

Delgado, R. (1997). Rodrigo's eleventh chronicle: empathy and false empathy. In R. Delgado \& J. Stefancic (Eds.), Critical white studies: Looking behind the mirror (pp. 614-618). Philadelphia: Temple University Press.

Delgado, R., \& Stefancic, J. (2001). Critical Race Theory: an Introduction. New York: New York University Press.

Doane, A. (2006). What is racism? Racial discourse and racial politics. Critical Sociology, $32(2 / 3), 255-274$.

ECB Racism Study Group. (1999). Clean bowl racism - going forward together: A report on racial equality in cricket. London: England and Wales Cricket Board.

Feagin, J., \& Vera, H. (1995). White racism. London: Routledge.

Fleming, S., \& Jones, C. (2007). 'I'd rather wear a turban than a rose': A case study of the ethics of chanting. Race, Ethnicity and Education, 10(4), 401-414.

Fletcher, T. (2011). The making of English cricket cultures: empire, globalization and (post) colonialism. Sport in Society, 14(1), 17-36.

Gillborn, D. (2008). Racism and education: Coincidence or conspiracy? Abingdon. Routledge.

Gillborn, D. (2011). Once upon a time in the UK: Race, class, hope and whiteness in the Academy (personal reflections on the birth of 'BritCrit'). In K. Hylton, A. Pilkington, P. Warmington, \& S. Housee (Eds.), op cit (pp. 21-38).

Glover, T. (2007). Ugly on the diamonds: An examination of white privilege in youth baseball. Leisure Sciences, 29, 195-208.

Goldberg, D.T. (1997). Racial subjects: Writing on race in America. London: Routledge.

Goldberg, D.T. (2009). The threat of race: Reflections on racial neoliberalism. Oxford: Wiley-Blackwell.

Goldberg, D.T. (2010). Call and response. Patterns of Prejudice, 40(1), 89-106.

Hartigan, J. (2010). Race in the 21 ${ }^{\text {st }}$ Century: Ethnographic approaches. Oxford: Oxford University Press.

Hutnyk, J. (2000). Critique of exotica: Music, politics and the culture industry. London: Pluto Press.

Hutnyk, J. (2005). The dialectic of here and there: anthropology 'at home' and British Asian communism. Social Identities, 11(4), 345-361.

Hylton, K. (2009). 'Race' and sport: Critical Race Theory. Abingdon. Routledge.

Hylton, K. (2010). How a turn to Critical Race Theory can contribute to our understanding of 'race', racism and anti-racism in sport. International Review for the Sociology of Sport, 45(3), 335-354.

Jimerson, J. (2001). A conversation (re)analysis of fraternal bonding in the locker room. Sociology of Sport Journal, 18, 317-338.

Kaur, R., \& Kalra, V. (1996). New paths for South Asian identity and musical creativity. In S. Sharma, J. Hutynk, \& A. Sharma (Eds.), Dis-orienting rhythms: The politics of the new Asian dance music (pp. 217-231). London: Zed Books.

King, C. (2004). Offside racism: Playing the white man. Oxford: Berg.

King, C.R. (2006). Defacements/effacements: Anti-Asian (American) sentiment in sport. Journal of Sport and Social Issues, 30(4), 340-352.

Leonard, D. (2004). The next M.J. or the next O.J.? Kobe Bryant, race, and the absurdity of colorblind rhetoric. Journal of Sport and Social Issues, 28(3), 284-313. 
Long, J. (2000). No racism here? A preliminary examination of sporting innocence. Managing Leisure, 5, 121-133.

Long, J., \& McNamee, M. (2004). On the moral economy of racism and racist rationalizations in sport. International Review for the Sociology of Sport, 39(4), 405-420.

Lusted, J. (2009). Playing games with 'race': Understanding resistance to 'race' equality initiatives in English local football governance. Soccer and Society, 10(6), 722-739.

McDonald, I., \& Ugra, S. (1998). Anyone for cricket? Equal opportunities and changing cricket cultures in Essex and East London. London: University of East London.

Malcolm, D. (1997). Stacking in cricket: A figurational sociological reappraisal of centrality. Sociology of Sport Journal, 14(3), 265-284.

Malcolm, D. (2001). 'It's not cricket': Colonial legacies and contemporary inequalities. Journal of Historical Sociology, 14(3), 253-275.

Malcolm, D. (2002). 'Clean bowled?': Cricket, racism and equal opportunities. Journal of Ethnic and Migration Studies, 28(2), 307-325.

Malcolm, D., Bairner, A., \& Curry, G. (2010). 'Woolmergate': Cricket and the representation of Islam and Muslims in the British press. Journal of Sport and Social Issues, $34(2), 215-235$.

Marqusee, M. (1998). Anyone but England: Cricket, race and class (2nd ed.). London: Two Heads Publishing.

Matsuda, M., Lawrence, C., Delgado, R., \& Crenshaw, K. (1993). Words that wound: Critical Race Theory, assaultive speech, and the First Amendment. Boulder, CO: Westview Press.

Müller, F., van Zoonen, L., \& de Roode, L. (2007). Accidental racists: Experiences and contradictions of racism in local Amsterdam soccer fan culture. Soccer and Society, $8(2 / 3), 335-350$.

Omi, M., \& Winant, H. (1994). Racial formation in the United States: From the 1960s to the 1990s (2nd ed.). London: Routledge.

Parker, L., \& Lynn, M. (2002). What's race got to do with it? Critical Race Theory's conflicts with and connections to qualitative research methodology and epistemology. Qualitative Inquiry, 8(1), 7-22.

Peach, C. (2006). Demographics of BrAsian settlement, 1951-2001. In N. Ali, V.S. Kalra, \& S. Sayyid (Eds.), op cit (pp. 168-181).

Picca, L., \& Feagin, J. (2007). Two-faced racism: Whites in the backstage and frontstage. Abingdon. Routledge.

Pickering, M., \& Lockyer, S. (2009). Introduction: The ethics and aesthetics of humour and comedy. In S. Lockyer \& M. Pickering (Eds.), op cit (pp. 1-26).

Pitcher, B. (2011). Developing transnational race theory: a place for CRT? In K. Hylton, A. Pilkington, P. Warmington, \& S. Housee (Eds.), op cit (pp. 196-206).

Puwar, N. (2005). Space invaders: Race, gender and bodies out of place. Oxford: Berg.

Ratna, A. (2011). Flying the flag for England? National identities and British Asian female footballers. In D. Burdsey (Ed.), op cit (pp. 117-130).

Robidoux, M. (2001). Men at play: A working understanding of professional hockey. Montreal: McGill-Queen's University Press.

Rumford, C. (2007). More than a game: globalization and the post-Westernization of world cricket. Global Networks, 7(2), 202-214.

Salmi, K. (2011). 'Race does not exist here': Applying Critical Race Theory to the French republican context. In K. Hylton, A. Pilkington, P. Warmington, \& S. Housee (Eds.), op cit (pp. 176-195).

Sayyid, S. (2006). Introduction: BrAsians - postcolonial people, ironic citizens. In N. Ali, V.S. Kalra, \& S. Sayyid (Eds.), op cit (pp. 1-10).

Spencer, N. (2004). Sister Act VI: Venus and Serena Williams at Indian Wells: 'sincere fictions' and white racism. Journal of Sport and Social Issues, 28(2), 115-135. 
Solórzano, D. (1998). Critical Race Theory, racial and gender microaggressions, and the experiences of Chicana and Chicano scholars. International Journal of Qualitative Studies in Education, 11(1), 121-136.

St. Louis, B. (2005). Brilliant bodies, fragile minds: race, sport and the mind/body split. In C. Alexander \& C. Knowles (Eds.), Making race matter: Bodies, space and identity (pp. 113-131). Basingstoke: Palgrave.

Steen, R. (2004) Calypso collapso. Observer, 25 July.

Sue, D.W. (2010). Microaggressions in everyday life: Race, gender, and sexual orientation. Hoboken, NJ: Wiley.

Sue, D.W., Capodilupo, C., Torino, G., Bucceri, G., Holder, A., Nadal, K., et al. (2007). Racial microaggressions in everyday life: Implications for clinical practice. The American Psychologist, 62(4), 271-286.

Tate, W. (1997). Critical Race Theory and education: History, theory, and implications. Review of Research in Education, 22, 195-247.

Thangaraj, S. (2010). 'Liting it up': Popular culture, Indo-Pak basketball, and South Asian American institutions. Civil Cosmopolitan Societies: an Interdisciplinary Journal, 2(2), 71-91.

Trepagnier, B. (2006). Silent racism: How well-meaning white people perpetuate the racial divide. Boulder, $\mathrm{CO}$ : Paradigm.

van Dijk, T. (1992). Discourse and the denial of racism. Discourse \& Society, 3(1), 87-118.

Visram, R. (2002). Asians in Britain: 400 Years of History. London: Pluto Press.

Wagg, S. (2007). 'To be an Englishman': Nation, ethnicity and English cricket in the global age. Sport in Society, 10(1), 11-32.

Weaver, S. (2010). The 'Other' laughs back: Humour and resistance in anti-racist comedy. Sociology, 44(1), 31-48.

Williams, J. (2001). Cricket and race. Oxford: Berg.

Williams, S. (2003). 'Paki cheats!': Postcolonial tensions in England-Pakistan cricket. In J. Bale \& M. Cronin (Eds.), Sport and Postcolonialism (pp. 91-106). Oxford: Berg.

Wise, T. (2008). Speaking treason fluently: Anti-racist reflections from an angry white male. Berkeley, CA: Soft Skull Press.

Wise, T. (2009). Between Barack and a hard place: Racism and white denial in the age of Obama. San Francisco: City Lights Books. 